\title{
The Medical Tourism Industry in Iran: A Review of Websites Designed for Cross-border Patients
}

\author{
Abdolvahab Baghbanian ${ }^{1}$, Reza Safdari (iD) ${ }^{2}$, Leila Erfannia ${ }^{3,4,{ }^{*}}$ and Mojtaba Zokaee ${ }^{5}$ \\ ${ }^{1}$ University of Adelaide, South Australia, Australia \\ ${ }^{2}$ Department of Health Information Management, School of Allied Medical Sciences, Tehran University of Medical Sciences, Tehran, Iran \\ ${ }^{3}$ Zahedan University of Medical Sciences, Iran \\ ${ }^{4}$ Clinical Education Research Centre, Shiraz University of Medical Sciences, Shiraz, Iran \\ ${ }^{5}$ Shahid Bahonar University of Kerman, Kerman, Iran \\ "Corresponding author: Department of Health Information Technology, Paramedical School, Zahedan University of Medical Sciences, Zahedan, Iran. Email \\ leila.erfannia@gmail.com
}

Received 2020 August 12; Revised 2021 January 31; Accepted 2021 February 05.

\begin{abstract}
Background: Cross-border health care, whether sanctioned by the governments (out-of-country care) or initiated by the patients (medical tourism), is on the rise globally. The medical tourism industry has shown great potential for improvement in Iran.

Objectives: We aimed to examine the representation of data elements on Iranian public and private medical tourism websites and evaluate their content maturity.

Methods: A descriptive cross-sectional design was used to gather and statistically analyze data from 12 medical tourism websites. Results: The highest level of data representation was provided for medical tourism attractions and destinations, followed by the geographical location of hospitals and the establishment of tourist agencies. Very few websites featured data elements on admission forms. Fisher's exact test revealed no statistically significant difference in the representation of data elements between the providers of medical tourism websites $(\mathrm{P}>0.05)$. Most privately owned medical tourism websites and only one in the public sector had a moderate-content status. No website was confirmed to be rich or poor regarding their maturity.

Conclusions: More investment is required for the development of information and communication technology infrastructures in the Iranian medical tourism industry to attract foreign service-users, although many other factors such as political and economic forces may be involved.
\end{abstract}

Keywords: Iran, Website, Medical Tourism, Medical Tourist, Health Care, Cross Border, Data Element

\section{Background}

Cross-border health care' denotes a broad social phenomenon involving the movement of patients, providers (e.g., physicians), or services (e.g., biopsy samples) across national boundaries for health care reasons $(1,2)$. It encompasses various concepts, such as medical tourism, inbound and outbound, or incoming and outgoing medical travelers (2). It may be sanctioned by the government (out-of-country-care) or initiated by the patient (medical tourism). Government-sanctioned outbound care usually involves insured procedures that create a delay that may pose catastrophic risks to the patient's health. Medical tourism, however, is often planned and coordinated by the patients without the inclusion of a public health insurance system (1-3). It excludes emergency and unplanned care for illnesses or complementary and alternative medicine (4). It also refers to medical professionals traveling inter- nationally to provide medical services (2). Although not a new concept, medical tourism has emerged as a flourishing industry for medical treatment (3). In this study, the definition is confined to international visitors who consider going abroad to receive medical services.

For many years, it has been common for people from under-developed or developing nations to travel to developed countries to benefit from advanced and innovative medical services. Medical tourism has now changed this approach and incorporates bidirectional flows when people from all countries frequently travel across their international frontier to obtain certain health care, which is either too delayed, inaccessible, unaffordable, unavailable, of poor quality, or legally banned at their home country (57). The medical tourism industry has resulted in the formation of a new class of patients, called 'patients without borders', 'cross-border patients', or 'patients with passports' $(5,6)$. 
Available estimates show that the number of tourists traveling abroad for health care will reach 11 million tourists each year, with a projected annual growth of up to $25 \%$ for the next decade $(4,8-10)$. The global medical tourism market is also expected to rise to $\$ 28$ billion by the year 2024 (11). Asian, Middle East, and South American countries have played a major role in the growth of the medical tourism industry worldwide $(9,12)$. Iran has also experienced the growth of medical tourism in recent years, even though it has been practiced in the country for decades (13). In 2012, Iran hosted 3.3 million tourists (14), most of whom sought medical treatment (15). Likewise, in the first seven months of 2018 , over 4.7 million visitors arrived in Iran, of whom around 300,000, largely from Central Asian and Arab countries, were possibly attracted to the country's health care system $(16,17)$. Given the above, it is reasonable to believe that Iran has an extremely large scope for medical tourism to grow.

While features such as geographic proximity, low service cost, quality care, cultural similarities, or the commonality of religion may have played a key role in attracting medical tourists to Iran (18), Iran's potential contribution to medical tourism has been challenged by several factors, such as Internet connectivity, information and communication technology (ICT) infrastructure, and international relations due to the re-imposition of US-led sanctions on trade (19). In particular, access to well-designed and comprehensive online platforms has been recognized as the obvious prerequisite for building up a successful medical tourism industry (20-22). However, it is unclear what proportion of ICT development contributes to the Iranian medical tourism industry. Existing research argues that Iran faces an absence of well-established media and appropriate website contents to provide medical tourists with essential facilities and services (17, 22, 23). Yet, few studies have examined the structure, data elements, and performance of Iranian medical tourism websites. Little is known as to whether those websites are sufficiently established to attract medical tourists from other countries.

\section{Objectives}

This study examined the representation of data elements on Iranian public and private medical tourism websites, and further analyzed the content-maturity status of the websites concerning their providers (public or private). A data element is defined as an attribute of a data entity or a basic data unit with a name, definition, representation, and set of values for specific facts (24). In this study, data element representation means the frequency distribution of data, as it appears on the Iranian medical tourism websites.

\section{Methods}

This study used a cross-sectional design. A multi-phase process was followed to search and identify appropriate websites, and ensure the accuracy and replicability of the results. The search strategy included a manual search for a list of Iranian medical tourism websites via the Google Search Engine. English and equivalent Persian keywords were used to facilitate the search strategy and retrieval of eligible websites. The keywords included (('medical tourism' or 'health tourism' or 'health travel' or 'medical travel' or 'cross-border healthcare' or 'international patient' or 'cross-border treatment' or 'medical tourist' or 'medical traveler' or 'health tourist' or 'health traveler') and ('Iran')). Only updated websites that focused on medical tourism, had English language facilities, and complied with the Iranian Ministry of Health's guidelines on medical tourism were selected. In total, 12 websites met the eligibility criteria and were reviewed in the last quarter of 2018.

A checklist with 15 items was designed to collect data. Six medical tourism advisors, Information Technology experts, and clinical practitioners verified the content validity of the checklist. It was primarily based on the Iranian Ministry of Health's policies and procedures and addressed questions about the content of the websites, including providers' demographics, average hospital stay, medical treatment rates, and service costs, payment methods, the existence of online admission, tourist offices, and hospitality services, insurance companies, procedures to resolve any dispute, the presence of patient debate forums and polling pages, information about hospitals, the option for patient consultation, and the possibility of follow-ups through the websites.

Collected data were coded and imported into SPSS software (V22.0) for analysis. Descriptive statistics and nonparametric Fisher's Exact test with a significance level of $\alpha=0.05$ were used to analyze data. Descriptive statistics were used to determine the frequencies of data elements. Each data element was then reviewed and classified into one of the three categories of patient choice and preference, patient-provider communication, and patient involvement.

The portrayal of each data element, i.e., the frequency distribution of data as appeared on the websites, was evaluated and used to plot the maturity position of the medical tourism information on the selected websites. The total value (scores) of these data elements and their distributions were used to demonstrate the maturity of the selected medical tourism website on a spectrum of poor, moderate, or rich-sourced websites. The websites with a total score between 0.00 and 4.99 were classified as poor, those with a score between 5.00 and 9.99 were classified 
as moderate, and those with a total score between 10.00 and 15.00 were grouped into the rich-sourced category. Fisher's Exact test (because of the small sample size) was used to evaluate the differences between the frequency of presented data and the type of medical tourism provider.

Ethics approval was not required for this study, as it was based on the analysis of existing texts without human involvement, and data were obtained anonymously from the selected websites.

\section{Results}

Twelve websites were listed as gateways for the medical tourism industry in Iran. Three websites were run by public organizations, whereas the other nine websites were operated by the private sector.

Data elements related to the "patient choice" category had the highest frequency. The recognition or presentation of Iran's tourist attractions or destinations had the highest level of representation (75\%). The data elements related to the existence of 'hospital map or its geographical location' and 'the introduction of tourism agencies' both equally ranked second (66.7\% and $66.7 \%$, respectively). The introduction of medical facilities and presentation of medical specialties had an equal representation of $58.3 \%$. Medical specialists appeared in the next position (41.6\%), followed by medical tariffs (33.4\%), payment methods (33.3\%), and the overview of insurance companies (25\%). Patient follow-up and monitoring of discharged patients or the existence of a complaint system for patients were substantially under-represented on the websites at the time the study was conducted. No website contained data elements related to the online admission system (Table 1). There was no statistically significant relationship between the data element representation and types of medical tourism providers (public vs. private) $(\mathrm{P}>0.05)$.

In addition, Figure 1 shows the status of data element representation as appeared in the private and public medical tourism websites in Iran. According to this figure, most privately operated medical tourism websites were placed in a moderate position due to having the majority of the required data elements in their websites, while no featurerich website was located. Only one public website had moderate content.

\section{Discussion}

A multifaceted array of factors drives the world's medical tourists to travel abroad to seek health care. The medical tourism industry has shown considerable potential for development in Iran. This cross-sectional study examined the representation of data elements on 12 Iranian public and private medical tourism websites and further analyzed the position of those websites concerning their operators (public or private). The highest frequency of data elements was related to the patient choice category, implying that available medical tourism websites offered services that could impact international clients when choosing Iran as their tourism destination. This category had the highest frequency of data elements, such as the recognition of tourist attractions in Iran, geographical access to service providers, and the identification of travel agencies. This is largely due to the ancient history of Iran and the abundance of tourist attractions in the country that can inspire medical tourism providers to use this attribute as a platform to attract international travelers and patients.

The second highest frequency value of data elements in this category belonged to the presentation of medical specialists and specialties through the website. Usually, Iranian medical tourism providers concentrate on medical specialists from a range of fields, besides their experience, talents, and reputation, in order to introduce quality services and attract medical tourists. In comparison with other data elements, the representation of the "patient-provider communication" category through medical tourism websites had the lowest frequency. One possible reason is that medical tourism providers in Iran do not offer live or telehealth services via their websites.

The key aspects of the study websites, which make them less effective in attracting medical tourists, have been identified as the lack of patient involvement in decisions associated with their treatment, such as the absence of patient complaints and suggestion procedures. While it is possible to improve the quality of services and satisfaction by engaging patients in the care process (25), only two websites clearly showed that feedback or suggestion mechanisms are used to assess medical tourists' views on services they required or had received. Previous research has shown that the existing medical tourism industry in Iran, including the associated ICT infrastructure and websites, has been underdeveloped and is not practical enough to retain consumer interest $(17,22,23)$. These studies argue that the use of such websites does not allow patients to survey their needs, opinions, or feedback.

In the present study, most websites observed had a moderate content status in terms of data element representation. Private-sector websites, in particular, showed a better position relative to publicly run websites. Data shared through private medical tourism websites were more accessible than information shared through public ones. This finding suggests that the private sector, including private hospitals and medical centers, plays a major 


\begin{tabular}{|c|c|c|c|}
\hline Data Elements & Governmental Provider (\%) & Private Provider (\%) & Total (\%) \\
\hline Presentation of medical specialists & 8.3 & 33.3 & 41.6 \\
\hline Presentation of specialized medical fields & 25 & 33.3 & 58.3 \\
\hline Average length of hospitalization & 0 & 16.7 & 16.7 \\
\hline Introducing payment method & 8.3 & 25 & 33.3 \\
\hline Existence of online admission forms & 0 & 0 & 0 \\
\hline Introducing tourism agencies & 16.7 & 50 & 66.7 \\
\hline Introducing medical facilities & 0 & 58.3 & 58.3 \\
\hline Introducing insurance companies & 8.3 & 16.7 & 25 \\
\hline Presentation of patient complaints procedure & 0 & 0 & 0 \\
\hline Existence of patient poll pages & 0 & 16.7 & 16.7 \\
\hline Existence of hospital geography and map & 16.7 & 50 & 66.7 \\
\hline Introducing tourism attractions & 25 & 50 & 75 \\
\hline Existence of options for patient consultation & 0 & 16.7 & 16.7 \\
\hline Possibility of patient follow-up after being discharged & 0 & 8.3 & 8.3 \\
\hline
\end{tabular}

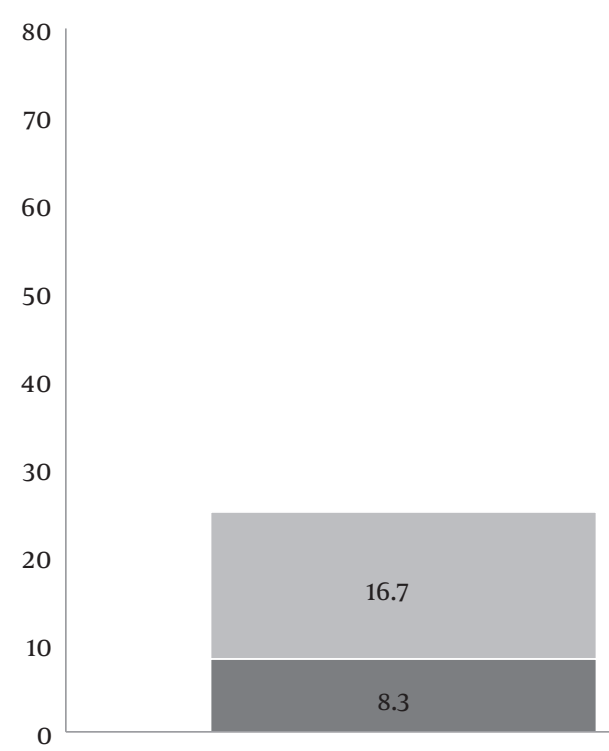

Government Websites

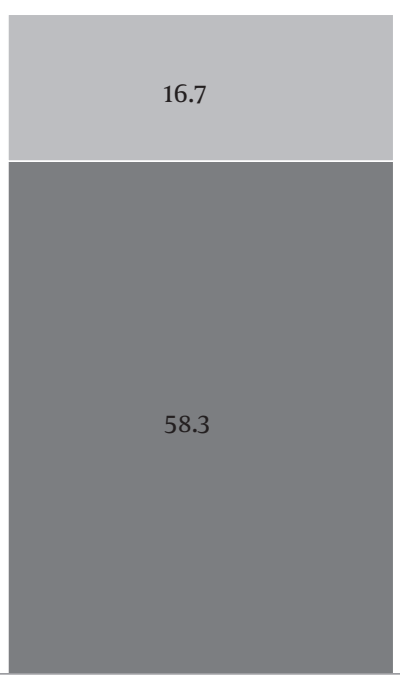

Private Websites

Figure 1. Comparison of data element representation between private and public providers/operators of medical tourism websites

role in promoting the medical tourism industry in Iran.

While previous research suggests that strong collaboration between the public and private sectors would ultimately help to bring the medical tourism industry of Iran to success (23), there is reasonable ground to believe that this study does not always see a mutually beneficial or har- monized relationship between private and public sectors. In this study, it was, therefore, hypothesized that the private sector is more efficient than the public sector for representing data elements on its own websites; however, no significant differences were found between the providers' type and data element representation. Yet, this research 
might pose some bias due to its small sample size.

Given the unique characteristics of Iran's moderate climate, neighborhood, appropriate medical infrastructure, and resources, as well as cultural and religious similarities, the country can see its medical tourism industry's rapid development relative to Middle East countries in the very near future. This requires the use of appropriate ICTs by medical tourism providers to support such improvements while maintaining quality, safety, effectiveness, and efficiency. In particular, they are required to take a more active role in their interaction with tourist-patients, involve them in the care process and respect their choices/preferences by adopting high-quality and technically up-to-date websites. Future research may explore the data representation of more medical tourism websites in different contexts, and may also incorporate other variables to determine the maturity of these websites for the delivery of services to medical tourists.

Another fundamental aspect for the growth of medical tourism in Iran is the electronic interaction and collaboration between providers and patients, including the use of online consultation, e-mails, chat rooms, and telefollow-ups. There are a large number of healthcare tourists and travel agencies that help medical professionals get their jobs done, provide electronic payment facilities, and promote medical records exchange. However, at the time of this study, most of the Iranian medical tourism websites lacked these facilities. If Iranian medical tourism providers want to compete in the medical tourism industry and make a contribution to the economy, they should provide safe and secure electronic services. While little is known about what inspires a medical tourist to choose a specific destination, more ICT infrastructure investment, high-quality health care, access to web-based services, and easy access to affordable, safe care, and strong public-private collaboration would make Iranian medical tourism more popular (26).

It is believed that this study has implications for designing customized websites for medical tourism in order to facilitate informed decisions for cross-border patients.

\subsection{Conclusions}

Even though the Iranian medical tourism industry has the potential to attract more foreign service-users, the current size and breadth of medical tourism websites in Iran are not large enough to sustain the industry. Healthcare professionals and decision-makers may consider adopting well-developed medical tourism websites by investing in ICT infrastructures in order to attract more medical tourists. Other factors, such as political and economic forces, may also be involved. If the Iranian medical tourism industry would attract more medical travelers, it needs to ensure access to well-develop websites with information on services' quality, consistency and continuity of care, online admission, regular monitoring and tracking, and resolution of disputes.

\section{Acknowledgments}

We would like to thank those who supported us in conducting this research.

\section{Footnotes}

Authors' Contribution: Study concept and design: L.E. and R.S.; Data extraction: L.E. and M.Z.; Analysis: L.E.; Interpretation of data: L.E., A.B., and R.S.; Drafting of the manuscript: L.E. and A.B.; Critical revision of the manuscript for important intellectual content: A.B. and L.E.; Statistical analysis: L.E. Editing and proofreading: A.B.

Conflict of Interests: The authors declared no conflict of interest.

Ethical Approval: This study did not involve any person, human sample, or medical record.

Funding/Support: The author(s) received no financial support for the research, authorship, and/or publication of this article.

Informed Consent This study did not involve any human subjects.

\section{References}

1. Footman K, Knai C, Baeten R, Glonti K, McKee M. Cross-border health care in Europe. Copenhagen, Denmark:: World Health Organization; 2014.

2. Rai A. Medical tourism: An introduction. In: Crooks V, editor. Medical tourism in Kolkata, Eastern India.1st ed. Switzerland: Springer; 2019. p. $1-41$.

3. Runnels V, Labonte R, Packer C, Chaudhry S, Adams O, Blackmer J. Canadian physicians' responses to cross border health care. Global Health. 2014;10(1):20. doi: 10.1186/1744-8603-10-20. [PubMed: 24708810]. [PubMed Central: PMC4233639].

4. Global Healthcare Resources. 2016-2017 global buyers survey. Florida: Global Healthcare Resources (GHR); 2017. Available from: https://documents.pub/document/2016-2017-global-buyerssurveymedic-global-buyers-survey-this-is-3-4-of-the.html.

5. MacKay D. Patients with passports: Medical tourism, law, and ethics. Kennedy Inst Ethics J. 2016;26(3):1-10. doi: 10.1353/ken.2016.0030.

6. Frenz M. Introduction: Medical tourism or movement for healthcare? Reflections on (inter-)national cross-border mobility. Glob Public Health. 2019;14(3):321-5. doi: 10.1080/17441692.2018.1515971. [PubMed: 30182814].

7. Noree T. The impact of medical tourism on the domestic economy and private health system: A case study of Thailand [thesis]. London: London School of Hygiene \& Tropical Medicine; 2015.

8. Patients Beyond Borders. Medical Tourism Statistics \& Facts. USA: Patients Beyond Borders; 2019, [updated 25 Jan 2019]. Available from: https://www.health-tourism.com/medical-tourism/statistics/. 
9. Dalen JE, Alpert JS. Medical tourists: Incoming and outgoing. Am J Med. 2019;132(1):9-10. doi: 10.1016/j.amjmed.2018.06.022. [PubMed: 30016635].

10. Freire NA. The emergent medical tourism: Advantages and disadvantages of the medical treatments abroad. Int Bus Res. 2012;5(2). doi: 10.5539/ibr.v5n2p41.

11. Health-Tourism. Medical tourism statistics and facts. Canada: HealthTourism.com; 2020. Available from: https://www.health-tourism. com/medical-tourism/statistics/.

12. Herrick DM. Medical tourism: Global competition in health care. 2007. Contract No.: 304.

13. Haji Ahmadi S, Hosseini SM, Jafari M. Factors affecting the attraction of medical tourists in iran. Int J Med Rev. 2017;4(2):47-51. doi: 10.29252/ijmr-040204.

14. Naami A, Chatrooz A. [Systematic review of medical tourism in Iran and case study of Tehran University of Medical Sciences]. J Payavard Salamat. 2018;11(5):598-609. Persian.

15. AriaMedTour. Arab patients increasingly travelling to Iran for medical services. 2018. Available from: https://ariamedtour.com/.

16. Youngman. Medical travel and tourism, global market report. International medical travel journal; 2019. Available from: https://www.imtj.com/resources/medical-travel-and-tourismglobal-market-report-1st-edition/.

17. Rokni L, Park S-H. Medical tourism in Iran, reevaluation on the new trends: A narrative review. Iran J Public Health. 2019;48(7). doi: 10.18502/ijph.v48i7.2941. [PubMed: 31497540]. [PubMed Central: PMC6708548].

18. Rahimi Zarchi MK, Jabbari A, Hatam N, Bastani P, Shafaghat T, Fazelzadeh O. Strategic analysis of Shiraz medical tourism industry: a mixed method study. Galen Medical J. 2018;7:1021. doi: 10.22086/gmj.v0io

19. Youngman I. Sanctions and travel restrictions still in place. International medical travel journal; 2016. Available from: https://www.imtj.com/ news/sanctions-and-travel-restrictions-still-place/.

20. Hong YA. Medical tourism and telemedicine: A new frontier of an old business. J Med Internet Res. 2016;18(5). e115. doi: 10.2196/jmir.5432. [PubMed: 27215230]. [PubMed Central: PMC4895094].

21. Khammarnia M, Baghbanian A, editors. The establishment of telemedicine network at hospitals affiliated with Iran University of Medical Sciences. First International Public Health Conference \& Eighteenth National Public Health Colloquium. Kuala Lumpur, Malaysia. Universiti Kebangsaan Malaysia Medical Center; 2010.

22. Samadbeik M, Asadi H, Mohseni M, Takbiri A, Moosavi A, Garavand A Designing a medical tourism website: A qualitative study. Iran J Public Health. 2017;46(2):249-57. [PubMed: 28451562]. [PubMed Central: PMC5402785].

23. Momeni K, Janati A, Imani A, Khodayari-Zarnaq R. Barriers to the development of medical tourism in East Azerbaijan province, Iran: A qualitative study. Tour Manag. 2018;69:307-16. doi: 10.1016/j.tourman.2018.05.007.

24. Symons CR, Tijsma P. A systematic and practical approach to the definition of data. Comput J. 1982;25(4):410-22. doi 10.1093/comjnl/25.4.410.

25. Jabbari A, Rahimi Zarchi MK, Kavosi Z, Shafaghat T, Keshtkaran A. The marketing mix and development of medical tourism in shiraz. Mater Sociomed. 2013;25(1):32-6. doi: 10.5455/msm.2013.25.32-36. [PubMed 23678337]. [PubMed Central: PMC3650564].

26. Hadian M, Jabbari A, Mousavi SH, Sheikhbardsiri H. Medical tourism development: A systematic review of economic aspects. Int J Healthc Manag. 2019:1-7. doi:10.1080/20479700.2019.1677977. 